\title{
Diving behavior of blue-footed boobies Sula nebouxii in northern Peru in relation to sex, body size and prey type
}

\author{
Carlos B. Zavalaga ${ }^{1, *}$, Silvano Benvenuti ${ }^{2}$, Luigi Dall'Antonia ${ }^{2}$, Steven D. Emslie ${ }^{1}$ \\ ${ }^{1}$ Department of Biology and Marine Biology, University of North Carolina, 601 South College Road, Wilmington, \\ North Carolina 28403-5915, USA \\ ${ }^{2}$ Dipartimento di Biologia, University of Pisa, Via Volta 6, 56126, Pisa, Italy
}

\begin{abstract}
We studied the diving behavior and diet of the sexually size-dimorphic blue-footed booby Sula nebouxii (BFB) breeding on Isla Lobos de Tierra, Peru, to evaluate whether sexual dimorphism is associated with feeding niche divergence between the sexes. We also discuss the foraging behavior of BFBs in relation to what is known about the vertical distribution of their main prey, and compare the BFB's foraging behavior with that of other tropical and temperate Sulidae. After analyzing data on 23 females and 28 males, we found no sexual differences in diet composition, crop mass, trip length, number of trips per day, proportion of time in flight and on the water, and number of dives per hour. We argue that this is because males and females were foraging in the same areas close to their colony. Conversely, females dived significantly deeper and longer, and consumed larger prey than males indicating that segregation may occur underwater. Body size (regardless of sex) was positively correlated to dive depth and prey size, suggesting that feeding niche separation is mediated by size dimorphism. However, the effects of body size and sex on foraging behavior could not be separated. BFBs and larger temperate gannets attained similar depths, but BFBs dived much deeper than did tropical boobies. The Peruvian anchovy Engraulis ringens was the most important prey consumed by BFBs, accounting over 79 to $97 \%$ of the total mass of the regurgitations. The temporal distribution of dives and dive profiles seems to be linked to the behavior and vertical distribution of anchovies.
\end{abstract}

KEY WORDS: Foraging niche segregation · Blue-footed boobies $\cdot$ Sula nebouxii $\cdot$ Sexual dimorphism · Diving behavior · Peruvian anchovies

\section{INTRODUCTION}

The feeding niche segregation hypothesis proposes that sexual size-dimorphism evolved through disruptive selection on the sexes to avoid food competition (Darwin 1871). Ecological differences exist in sexually dimorphic birds (e.g. Hedrick \& Temeles 1989, Shine 1989), although it is still unclear whether the origin and maintenance of this dimorphism is the result of differential niche exploitation between the sexes or of other plausible and not mutually exclusive processes such as reproductive role division (e.g. Andersson \& Norberg 1981) and sexual selection (Andersson 1994). The sex- ual selection hypothesis predicts that differences in traits between males and females evolved either through competition for access to mates, generally determined by contests, or through choice of highquality mates. This hypothesis has received more acceptance than the ecological model because of its parsimony, predictability, and testability, whereas the latter has been difficult to test because data on resource availability and use by both sexes have been difficult to obtain (Shine 1989). Evaluation of the feeding niche segregation hypothesis as a mechanism to reduce food competition between males and females has been made possible in recent years through new 
advances in the miniaturization of electronic devices, which have allowed detailed and more accurate studies of sex-specific foraging behavior of free-ranging birds, in particular marine birds (e.g. Ropert-Coudert et al. 2004a, Paredes et al. 2005, Weimerskirch et al. 2005b, 2006).

Sex-specific information of at-sea spatial distribution, diving behavior, diet, and activity budgets in several species of seabirds have revealed that segregation of feeding niches may play an important role in the maintenance of sexual size-dimorphism. For instance, sexual differences in wing morphology of wandering albatrosses Diomedea exulans (Shaffer et al. 2001) and body mass of northern giant petrels Macronectes halli (González-Solís et al. 2000) have an ecological significance in reducing food competition, with larger males occupying different niches than smaller females.

Unlike other seabirds, females are significantly bigger than males in the Stercorariinae (jaegers and skuas), Phaethontidae (tropicbirds), Fregatidae (frigatebirds) and Sulidae (gannets and boobies). The sulids are good candidates for testing the niche segregation hypothesis because (1) the degree of sexual sizedimorphism varies considerably from the monomorphic northern gannet Morus bassana to the highly dimorphic brown booby Sula leucogaster, and (2) they breed in areas with different marine productivity, from the poor tropical waters of red-footed boobies (S. sula) to the nutrient-rich upwelling waters of Peruvian boobies ( $S$. variegata). Furthermore, the magnitude of foraging segregation is more marked in the highly dimorphic brown booby (females $38 \%$ larger) than in the less dimorphic red-footed booby (females 15\% larger), suggesting that body size may be associated with the separation of feeding niches (Lewis et al. 2005). If body size differences between sexes facilitate feeding niche segregation in tropical boobies, then sex-specific differences in foraging behavior may also be expected in the highly dimorphic blue-footed booby S. nebouxii (BFB).

BFBs are tropical seabirds displaying marked reversed sexual size-dimorphism, with females approximately 30 to $32 \%$ heavier and 5 to $10 \%$ larger than males (Guerra \& Drummond 1995). There are numerous studies on BFB behavioral ecology (e.g. Drummond et al. 1991, Velando \& Alonso-Alvarez 2003), but their foraging behavior has remained poorly understood. It appears that BFBs are well adapted to exploit shallow inshore waters (Nelson 1978) with dives of short duration (Duffy 1987). In the Galápagos Islands, radio-tracked BFBs fed closer to the colony than did Nazca boobies (Sula granti), which preferentially foraged over seamounts with markedly lower productivity than in the Peruvian upwelling (Anderson \& Ricklefs 1987). The sardine Sardinops sagax sagax is the predominant prey in the Galápagos (Anderson \& Ricklefs 1987), but in Peru BFBs consume up to 15 species of fish (Janhcke \& Goya 2000). There are no data on their diving behavior and its association to prey type, and it is not known whether females and males diverge in their foraging niches as a result of sexual dimorphism. BFBs have sex-specific responses to parental effort, with larger females being able to (1) regulate their body mass during periods of food stress (Velando \& Alonso-Alvarez 2003), (2) collect larger amounts of food per hour spent at sea (Anderson \& Ricklefs 1992), and (3) deliver food to their chicks more frequently than males (Guerra \& Drummond 1995). Differential foraging behavior between the sexes may contribute to this disparity.

To investigate this disparity, we measured the sexspecific diving behavior and at-sea activity budgets of chick-rearing BFBs using small time-depth recorders/ flight sensors during 2 seasons at Isla Lobos de Tierra, northern Peru. Additionally, we collected information on diet composition and prey size to examine possible relationships between the diving characteristics of male and female BFBs and what is known about the vertical distribution and behavior of their main prey. Finally, we compared the foraging behavior of BFBs with that of other tropical and temperate sulids.

\section{MATERIALS AND METHODS}

We studied the foraging behavior of breeding BFBs on Isla Lobos de Tierra, northern Peru $\left(6^{\circ} 24^{\prime} \mathrm{S}\right.$, $80^{\circ} 51^{\prime} \mathrm{W}$ ), during 2 field seasons characterized by different oceanographic conditions and breeding status: 28 June to 21 July 2002 (sea surface temperature SST = 17 to $18^{\circ} \mathrm{C}$, mostly incubating birds) and 25 January to 27 February 2003 (SST $=21$ to $22^{\circ} \mathrm{C}$, adults attending chicks). Lobos de Tierra is a barren, inshore island (nearest distance to the mainland $=12 \mathrm{~km}$ ) with an estimated area of $1426 \mathrm{ha}(9 \times 3 \mathrm{~km})$. It is strongly influenced by warm tropical waters from the north and west, and cold upwelling waters from the south and east. These oceanographic fronts change both seasonally and annually, affecting the number (Guillén 1991) and diet composition (Jahncke \& Goya 2000) of BFBs. BFBs breed year round on Isla Lobos de Tierra, but a hatching peak occurs at the end of December (C. B. Zavalaga unpubl. data). They occupy almost 2-thirds of the island surface for breeding, with nests uniformly distributed in large sub-colonies (up to 10000 pairs) separated from each other by rocky hills. Although no systematic counts were undertaken during the study period, we estimated a breeding population of 75000 to 100000 pairs based on nest density and the total area occupied by breeding boobies. 
Dataloggers. Dataloggers were deployed on 18 and 57 breeding birds of known sex in 2002 and 2003, respectively. However, we only obtained reliable data from 9 birds (5 males, 4 females) in 2002 and 42 birds (23 males and 19 females) in 2003 because some devices failed to record data or fell off during deployment. The loggers ( $29 \mathrm{~g}, 23 \times 19 \times 97 \mathrm{~mm})$ accounted for $<2 \%$ of a bird's body mass (below the $5 \%$ limit recommended by the Ornithological Council Guidelines: www.nmnh.si.edu/BIRDNET/GuideToUse). These devices carried a depth meter and a flight sensor manufactured by the Istituto di Elaborazione dell'Informazione, CNR, Pisa, Italy, which have been field tested in other seabirds such as the thick-billed murre Uria lomvia (Benvenuti et al. 2002), the razorbill Alca torda (Benvenuti et al. 2001), and the northern gannet (Garthe et al. 2000). The depth meter had an operative range of 0 to $70 \mathrm{~m}$ and $1 \mathrm{~m}$ resolution. For the analysis of dive depths, all records $<1 \mathrm{~m}$ were excluded because these may reflect 'bathing splash' immersions (Lewis et al. 2002). The depth meters were used to determine dive depths, dive duration, timing of dives and number of dives per trip. The flight sensor was a modified microphone with a membrane activated by body movements and wing flapping, so the duration of different at-sea activities such as resting on the water, traveling (including plunging time), and diving could be measured by recognizing changes in the intensity and frequency of signals (Benvenuti et al. 2001, Lewis et al. 2002). The memory capacity of the dataloggers was $128 \mathrm{kB}$; the flight sensor was set to record data every $4 \mathrm{~s}$, whereas the depth sensor collected data at its highest resolution of $2 \mathrm{~s}$ intervals. The data were analyzed by the software application VISUA 3 (designed by A. Ribolini, IEI, CNR, Pisa).

The temporal resolution of the dataloggers can be long for plunge dives performed by boobies and may underestimate the number of shallow dives. To evaluate this potential bias, we measured the dive duration of 74 foraging BFBs by visual observations from a boat 9, 14, 23 and $28 \mathrm{~km}$ northeast of Isla Lobos de Tierra on 25 June 2002. Diving birds were followed with the aid of binoculars and dive duration was recorded with a chronometer to the nearest $0.01 \mathrm{~s}$ from the time the bird contacted the water after a plunge to the time it emerged at the surface. Only solitary foragers were sighted, usually within a radius of $<100 \mathrm{~m}$ from the boat.

Device attachment and bird measurements. Birds were captured and recaptured at their nests using a monofilament noose attached to a $3 \mathrm{~m}$ aluminum pole. The loggers were attached beneath the base of the 4 central tail feathers using 3 to 4 strips of Tesa tape. The procedure usually took $<5 \mathrm{~min}$ from capture to release. The deployment time varied from $4 \mathrm{~h}$ to $4 \mathrm{~d}$ (mode $=$ $1 \mathrm{~d})$, so multiple trips for the same individual could be recorded. Immediately upon their return, the birds were captured at the nest, the loggers retrieved and the adults weighed, measured and banded. The wing chord (WC, from the carpal joint to the tip of the largest primary) was flattened on a ruler and measured to the nearest $1 \mathrm{~mm}$. Culmen (CL) and tarsus (TL) length were measured with digital calipers to the nearest $0.01 \mathrm{~mm}$. Body mass (BM) was recorded by weighing the birds after regurgitation to the nearest $50 \mathrm{~g}$ with a Pesola spring balance. To examine the effects of body size on dive depths and prey size, body measurements were standardized (mean $=0, \mathrm{SD}=1$ ) and combined to calculate an index of body size using principal component analysis (PC1). Unlike body mass, a body size index represents a more precise and nonfluctuating measurement. The first component explained $84 \%$ of the total variance and was expressed by $\mathrm{PC} 1=0.52(\mathrm{BM})$ $+0.49(\mathrm{CL})+0.50(\mathrm{TL})+0.48(\mathrm{WC})$.

Because energetic constraints can affect foraging behavior, BFB molt was quantified in 2003 by counting the number of molting tail feathers and by scoring their relative length $(1=0-25 \%, 2=26-50 \%, 3=51-75 \%$ and $4=76-100 \%$ grown). For individual identification of birds from a distance, breast feathers were painted with biodegradable dye. The sex of each adult was determined by inspecting 3 different phenotypes: body size (females $31 \%$ heavier than males), dark central area of the iris (larger and more irregular in females), and calls (whistles in males, grunts in females; Nelson 1978).

Dietary analysis. Diet composition and prey size were assessed by analysis of stomach contents from induced regurgitations of 34 instrumented and 293 non-instrumented birds. Stomach samples from instrumented birds were obtained immediately upon their return from a feeding trip whereas those from noninstrumented birds were collected at random between 19:30 and 21:00 $\mathrm{h}$ either from the periphery of the breeding sites or at beaches. A non-invasive method for collection of stomach contents was preferred : BFBs can be made to regurgitate spontaneously by holding them upside down and pressing gently on their bellies until all the food has passed (as determined by the presence of bile). In $70 \%$ of the samples $(n=327)$, the stomach content was undigested, and therefore whole prey could be easily identified, sorted, and measured. Diet composition was expressed as a percentage of mass (mass of a particular prey item/mass of regurgitated food).

Total fish length (from the snout to the end of the tail fin) was assessed either by direct measurement of intact fish (accuracy $\pm 1 \mathrm{~mm}$ ), or in the case of partially digested Peruvian anchovies Engraulis ringens, by extracting an intact sagittal otolith and obtaining a digital measurement using a Zeiss Stemi SV 6 dissecting 
microscope with a digital SPOT RT camera attachment and Image-Pro Plus software (Opelco; accuracy $\pm 0.01 \mathrm{~mm})$. The initial anchovy length was estimated using the equation: fish length $(\mathrm{cm})=0.798+3.33$ (otolith length [mm]) (Castillo et al. 1999).

Control birds. To evaluate any affects of the dataloggers on BFB breeding and foraging performance, we compared the probability of nest failure, diet composition, and the length and number of feeding trips per day between instrumented and non-instrumented birds ( $\mathrm{n}=22$ in 2002 and 110 in 2003). Control (noninstrumented) birds were marked with the same dyes as the instrumented birds. The low nest density in BFB colonies on Isla Lobos de Tierra (modal internest distance $>3 \mathrm{~m}$ ) allowed us to randomly select central and peripheral nests, which we marked with numbered stones. The presence/absence of each bird was determined by observing the nests from the colony periphery (5 to $10 \mathrm{~m}$ away the nests) every $30 \mathrm{~min}$ from dawn to dusk. The duration of the foraging trip of control birds was defined as the time elapsed between departure and arrival at the nest. The duration of nest absence for both control and instrumented birds showed a bimodal distribution with short $(<1 \mathrm{~h}, 10 \%$ of all trips) and long ( $>1 \mathrm{~h})$ absences. The shortest successful trip (defined as when the bird brought food to the nest) was $45 \min (\mathrm{n}=10)$. Short absences $(<1 \mathrm{~h})$ may be associated with activities other than foraging such as bathing or resting on beaches. Thus, only absences $>1 \mathrm{~h}$ were selected for comparison of the duration of feeding trips between control and experimental nests. Because birds may compensate any increased foraging effort by their mates (Paredes et al. 2005), to avoid pseudo-replication only trips from 1 member of a breeding pair were considered in the calculation of feeding trip duration.

Statistical analysis. Most of the data collected either from the instruments (dive depth, number of dives, length of feeding trips, at-sea activity budgets and timing of dives) or from direct observations included multiple records of the same bird, and therefore the data could not be considered independent. To avoid pseudo-replication, we used generalized mixed linear models (GLM) using restricted maximum-likelihood estimations (REML) for comparisons between sexes, seasons, or instrumentation. In these models, these covariates were included as fixed factors, whereas bird identity was used as a random factor (Kuehl 2000). For single observations per bird (e.g. diet composition) a generalized linear model (GLM) was used (Kuehl 2000). BFBs mostly undertook 1 or 2 foraging trips $\mathrm{d}^{-1}$, and therefore the data could be best described by a binomial distribution ( 1 trip $=1,>1$ trip $=0$ ). Thus, for comparison of the number of trips per day between control and instrumented birds the logistic regression with Wald $-\chi^{2}$ estimations was used. When required, data were normalized using log $(x+1)$. The chi-square test was used for comparisons of nest failure, shape of dives and temporal distribution of dives in a feeding trip, whereas the Z-test was applied for comparisons of diet composition. Linear regression was performed to examine relationships between dive depth and duration, and dive depth and body size. Data are presented as means \pm 1 SD, except where otherwise indicated. Differences were considered significant at $\mathrm{p}<0.05$. All statistical analyses were performed using SAS Version 9.1.3.

\section{RESULTS}

\section{Effects of instrumentation and accuracy of dataloggers}

Overall, nest failure (expressed as the proportion of pairs that deserted their nests during the study period) was similar between instrumented birds $(13 \%, \mathrm{n}=23)$ and controls $\left(22 \%, \mathrm{n}=110 ; \chi^{2}=0.08, \mathrm{p}=0.77, \mathrm{df}=1\right)$. Birds with instruments spent less time foraging $(\bar{x}=$ $2.85 \pm 2.24 \mathrm{~h}, \mathrm{n}=84$ trips) than controls $(\bar{x}=3.25 \pm$ $2.18 \mathrm{~h}, \mathrm{n}=614$ trips); (REML $\log (\mathrm{x}+1), F_{1,94}=1.99, \mathrm{p}=$ 0.16 ). The likelihood of 1 or multiple trips (2 to 5 ) in a day was similar for instrumented and control birds (logistic regression, Wald $-\chi^{2}=1.95, \mathrm{p}=0.16$ ). The proportion of anchovies brought to the nest did not differ between instrumented birds and controls (instrumented $\bar{x}=93 \pm 19 \%, \mathrm{n}=34$; controls $\bar{x}=88 \pm 30 \%$, $\mathrm{n}=293$; $Z$-test, $Z=1.29, \mathrm{p}=0.19)$ and diet data from both groups were pooled for further analyses.

Mean dive duration of birds observed at sea was $3.17 \mathrm{~s}$ (range 1.66 to $5.65 \mathrm{~s}, \mathrm{n}=74$ ), shorter than that recorded by dataloggers (see 'Discussion'). The distribution of dives showed that only $4 \%$ of dives were shorter than $2 \mathrm{~s}$ (the datalogger sampling rate).

\section{Adult morphometry and molt}

BFB females were $31 \%$ heavier and 6 to $9 \%$ larger than males (Table 1). Overall, $88 \%$ of the total birds measured in $2003(\mathrm{n}=192)$ were molting their tail feathers. Quick inspection of some birds showed that molt also occurred simultaneously in primary, secondary, and contour feathers. Two out of 16 worn tail feathers were replaced during the last week of January and the last week of February (range 1 to 7 ) and this ratio was similar between sexes ( $t$-test, $t=1.41$, $\mathrm{df}=190, \mathrm{p}=0.16$ ). Likewise, the mean growth score of molting feathers did not vary between males $(\bar{x}=$ $2.14 \pm 0.92, \mathrm{n}=77)$ and females $(\bar{x}=2.00 \pm 0.90, \mathrm{n}=92)$ ( $t$-test, $t=0.99, \mathrm{p}=0.32$ ). 
Table 1. Sula nebouxii. Morphometric data on 169 females and 139 males breeding on Isla Lobos de Tierra, Peru, in 2002 and 2003. Data are means \pm SD (range). Results of Student's $t$-tests are presented for comparisons of means

\begin{tabular}{|c|c|c|c|c|}
\hline Measurement & Females & Males & $t$-test & $\mathrm{p}$ \\
\hline Body mass (g) & $1723 \pm 115(1350-2000)$ & $1319 \pm 80(1125-1500)$ & 34.97 & $<0.001$ \\
\hline Culmen length $(\mathrm{cm})$ & $10.68 \pm 0.31(9.88-11.45)$ & $9.95 \pm 0.26(9.16-10.69)$ & 21.91 & $<0.001$ \\
\hline Tarsometatarsus length (cm) & $5.79 \pm 0.21(5.17-6.28)$ & $5.30 \pm 0.14(4.76-5.66)$ & 23.47 & $<0.001$ \\
\hline Wing chord $(\mathrm{cm})$ & $43.27 \pm 1.07(40.4-46.6)$ & $40.92 \pm 0.99(38.3-43.8)$ & 19.70 & $<0.001$ \\
\hline
\end{tabular}

\section{Diet composition and prey size}

BFBs consumed 16 species of fish and 1 species of squid, but the Peruvian anchovy was by far the most important prey item, accounting for 79 to $97 \%$ of the total mass of the regurgitations (Table 2). Males and females consumed similar proportions of anchovies $\left(\right.$ GLM, $F_{1,326}=0.18, p=0.67$ ) (Table 2). Nevertheless, there was a significant difference in diet composition between years, with a lower proportion of anchovies in 2003 than in 2002 (GLM, $F_{1,326}=23.5, \mathrm{p}<0.001$ ) (Table 2). No significant interaction between season and sex was detected $\left(F_{1,326}=0.38, \mathrm{p}=0.53\right)$. Likewise, the mean mass of regurgitations from a sample of birds captured upon arrival at their nests was $101 \pm 65 \mathrm{~g}(\mathrm{n}=$ 73), and it was not significantly different between males $(\bar{x}=86 \pm 47 \mathrm{~g}, \mathrm{n}=34)$ and females $(\bar{x}=114 \pm$ $76 \mathrm{~g}, \mathrm{n}=39)\left(\mathrm{GLM} \log (x), F_{1,73}=0.81, \mathrm{p}=0.37\right)$, years $\left(\mathrm{GLM} \log (\mathrm{x}), F_{1,73}=0.27, \mathrm{p}=0.60\right)$ or the interaction between both factors $\left(F_{1,73}=0.34, \mathrm{p}=0.56\right)$.

Adult anchovies (total length $\geq 11 \mathrm{~cm}$ ) were the target age class preyed upon by BFBs ( $80 \%$ of the total number of anchovies consumed were adults). Females consumed significantly larger anchovies $(\bar{x}=12.53 \pm$
$1.52 \mathrm{~cm}, \mathrm{n}=856)$ than males $(\bar{x}=11.89 \pm 1.59 \mathrm{~cm}, \mathrm{n}=$ 724) $\left(\right.$ REML, $\left.F_{1,1330}=5.31, \mathrm{p}=0.02\right)$. Anchovies consumed were significantly smaller in $2002(\bar{x}=11.74 \pm$ $1.48 \mathrm{~cm}, \mathrm{n}=930)$ than in $2003(\bar{x}=12.95 \pm 1.44 \mathrm{~cm}$, $\mathrm{n}=650)\left(\mathrm{REML}, F_{1,1330}=202.9, \mathrm{p}<0.001\right)$. There were no significant sex $\times$ season interaction terms $\left(F_{1,1330}=\right.$ $2.08, p=0.15)$. When the data on all other prey species ( $\mathrm{n}=15$ species) were pooled, females still consumed larger items $(\bar{x}=12.27 \pm 3.97 \mathrm{~cm}, \mathrm{n}=137)$ than males $(\bar{x}=10.22 \pm 3.09 \mathrm{~cm}, \mathrm{n}=87)\left(\mathrm{REML}, F_{1,49}=12.42, \mathrm{p}<\right.$ 0.001). Fish length (all prey pooled) was positively correlated to $\mathrm{BFB}$ body size (Fish length $(\mathrm{cm})=12.62+$ 0.29 (PC1); $F_{1,50}=16.49, \mathrm{r}^{2}=0.063, \mathrm{p}<0.001$ ) (Fig. 1).

\section{Timing and duration of foraging trips}

Foraging activities (diving, swimming and flying) were restricted to daylight hours and all instrumented birds returned to the nest on the day of departure. The maximum trip duration recorded was $14 \mathrm{~h}$, showing that some birds could occasionally return to the colony during twilight and darkness. Trip length was similar between males $(\bar{x}=3.22 \pm 2.22 \mathrm{~h}, \mathrm{n}=328$ trips $)$ and

Table 2. Sula nebouxii. Sex-specific diet composition (mean \pm SD, \% by mass) in June and July 2002 (63 females, F; 61 males, M) and January and February 2003 (118 F; 85 M) at Isla Lobos de Tierra, Peru

\begin{tabular}{|c|c|c|c|c|c|}
\hline \multirow[t]{2}{*}{ Prey species } & \multirow[t]{2}{*}{ Scientific name } & \multicolumn{2}{|c|}{$-2002 \square$} & \multicolumn{2}{|c|}{2003} \\
\hline & & $\mathrm{F}$ & M & $\mathrm{F}$ & M \\
\hline Peruvian anchovy & Engraulis ringens & $98 \pm 2$ & $97 \pm 2$ & $79 \pm 4$ & $83 \pm 4$ \\
\hline Short-finned butterfish & Peprilus snyderi & - & - & $5 \pm 2$ & $9 \pm 3$ \\
\hline Long-nosed anchovy & Anchoa nasus & - & 0.5 & $2.5 \pm 1$ & $3 \pm 2$ \\
\hline Pacific mackerel & Scomber japonicus & - & - & $2 \pm 1$ & $1 \pm 1$ \\
\hline Pacific bumper & Chloroscombrus orqueata & - & - & $3 \pm 1$ & $1 \pm 0.5$ \\
\hline Horse mackerel & Trachurus murphyi & - & - & $3 \pm 1$ & - \\
\hline Squid & Loligo gayi & - & 0.7 & $1 \pm 1$ & $0.5 \pm 0.3$ \\
\hline Peruvian banded croaker & Palaronchurus peruanus & - & - & $1 \pm 1$ & - \\
\hline Peruvian weakfish & Cynoscion analis & - & - & $1 \pm 1$ & $1 \pm 1$ \\
\hline Striped mullet & Mugil cephalus & - & - & $1 \pm 1$ & - \\
\hline Palm ruff & Seriolella violacea & - & - & $1 \pm 1$ & - \\
\hline South Pacific sauri & Scomberesox saurus scombroides & $2 \pm 2$ & - & $1 \pm 1$ & $2 \pm 1$ \\
\hline Starry butterfish & Stromateus stellatus & - & - & 0.2 & - \\
\hline Gulf gurnard & Bellator gymnosthetus & - & - & - & 0.1 \\
\hline Peruvian silverside & Odontesthes regia regia & 0.1 & - & - & 0.1 \\
\hline Blue bobo & Polydactylus approximans & - & 0.9 & - & - \\
\hline Bighead tilefish & Caulolatilus affinis & - & 0.7 & - & - \\
\hline
\end{tabular}




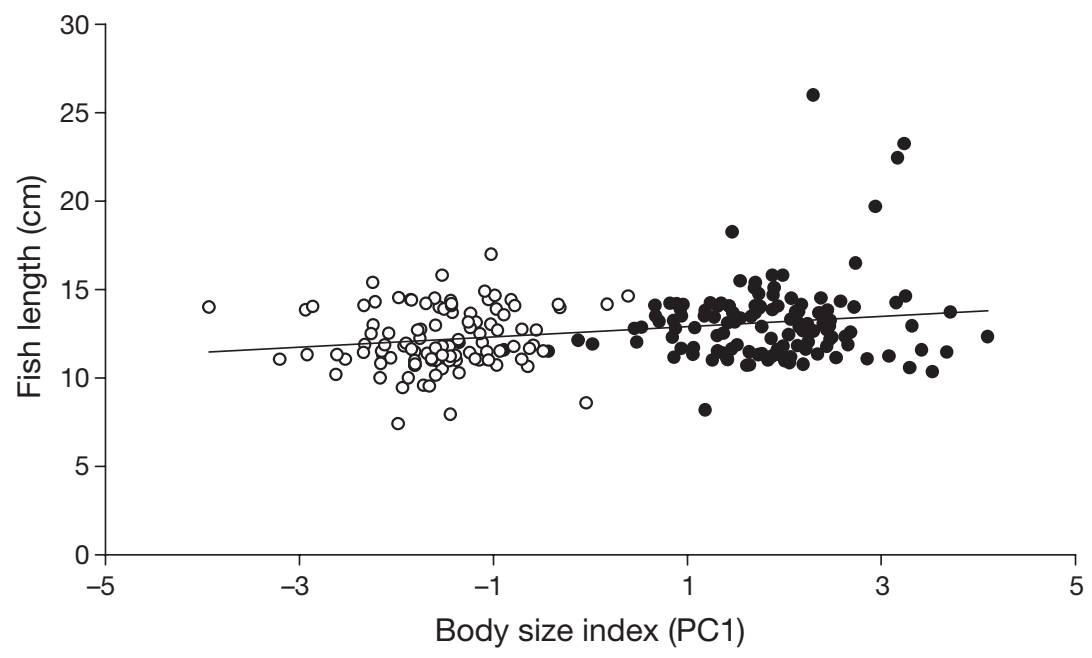

Fig. 1. Sula nebouxii. Relationship of prey size (cm) and body size index (principal component analysis) of 129 females (•) and 105 males (O)
$155 \min (\bar{x}=27.39 \pm 22.21 \min , \mathrm{n}=95$ trips). Nevertheless, when the duration of the foraging trip was divided into quintiles, the proportion of dives was not evenly distributed among segments: the proportion of dives in a trip increased from the first to the fourth quintile (from 11 to $31 \%$, respectively) and then decreased at the end of the trip (8\%, Fig. 3) when the birds returned to the colony. Males dived more frequently at the beginning and end of a feeding trip than did females $\left(\chi^{2}=32.9\right.$, df $=4, \mathrm{p}<$ 0.001).

Overall, BFBs spent $86 \%$ (range $=46$ to $99 \%, n=94$ trips by 46 birds) of their foraging time in flight. Resting on the water and diving accounted for $11 \%$ (range $=0$ to $52 \%$ ) and $3 \%$ (range $=$ 0.1 to $13 \%$ ) of a feeding trip, respectively. The proportion of time in flight was simifemales $(\bar{x}=3.13 \pm 2.17 \mathrm{~h}, \mathrm{n}=380$ trips) (REML log $\left.(x+1), F_{1,93}=0.09, p=0.76\right)$, but it was significantly longer in $2002(\bar{x}=4.35 \pm 2.47 \mathrm{~h}, \mathrm{n}=143$ trips $)$ than in $2003(\bar{x}=2.87 \pm 2.01 \mathrm{~h}, \mathrm{n}=565$ trips) (REML $\log (x+1)$, $\left.F_{1,93}=35.1, \mathrm{p}<0.001\right)$. Any seasonal effect on feeding trip duration was similar between sexes (season $\times$ sex interaction, $F_{1,93}=0.04, \mathrm{p}=0.84$ ). The likelihood of 1 or multiple trips in a day also was similar between sexes (logistic regression, Wald $-\chi^{2}=0.43, p=0.51$ ), but on average it was 7.75 times more likely that a bird performed more than 1 trip in 2003 (mode = 2 trips) than in 2002 (mode = 1 trip) (logistic regression, Wald $\left.-\chi^{2}=74.93, \mathrm{p}<0.001\right)$.

\section{Timing of dives and at-sea activities}

Diving activities of BFBs extended from sunrise to sunset (06:30 h to $18: 30 \mathrm{~h}$ in 2002 and 06:00 h to 19:00 h in 2003), with some immersions occurring during twilight hours (Fig. 2). The deepest dives were recorded during the period of high light intensity between 10:00 $\mathrm{h}$ and $14: 00 \mathrm{~h}(\bar{x}=14.31 \pm 3.42 \mathrm{~m}$, range $=11$ to $22, \mathrm{n}=13$ birds), but some birds ( $\mathrm{n}=3$ ) also dived as deep as 10 to $15 \mathrm{~m}$ during twilight hours (Fig. 2). Plunge-dives occurred almost during the whole of a trip. The time of the first plunge-dive in a feeding trip varied from 1 to $144 \mathrm{~min}$ after leaving the colony $(\bar{x}=23.45 \pm$ $23.62 \min , \mathrm{n}=95$ trips), whereas the interval between the last dive and the return to the nest ranged from 2 to

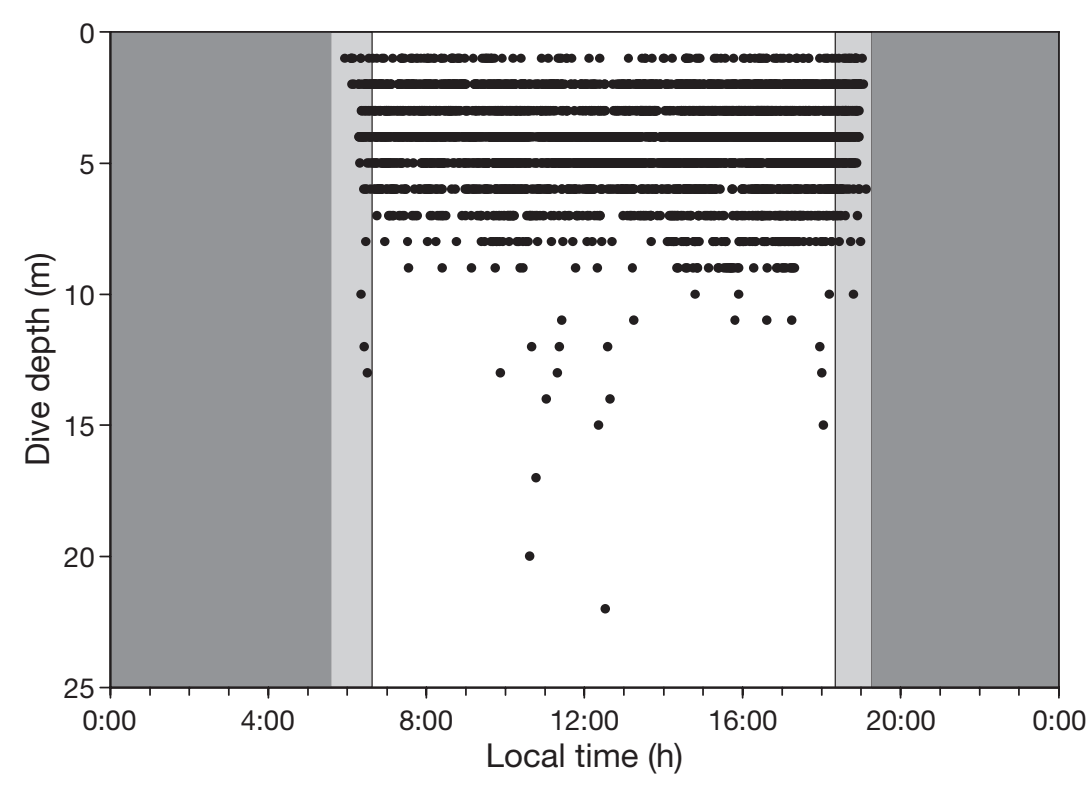

Fig. 2. Sula nebouxii. Diving depth in relation to time of day at Isla Lobos de Tierra, Peru. Individual dives $(\mathrm{n}=4133)$ are shown $(\bullet)$; open area encloses all dives between sunset and sunrise; light and dark gray shading symbolizes twilight and darkness, respectively 
Table 3. Sula nebouxii. Dive depth and duration, number of dives trip ${ }^{-1}$ and no. of dives $\mathrm{h}^{-1}$ for 23 females (F) and 28 males (M) on Isla Lobos de Tierra, Peru. Data are means \pm 1 SD (range); sample size

\begin{tabular}{|c|c|c|c|c|}
\hline \multirow[t]{2}{*}{ Parameters } & \multicolumn{2}{|c|}{2002} & \multirow[b]{2}{*}{$\mathrm{F}$} & \multirow[b]{2}{*}{$\mathrm{M}$} \\
\hline & $\mathrm{F}$ & M & & \\
\hline Dive depth (m) & $3.9 \pm 1.5(1-11) ; 510$ & $3.3 \pm 1.2(1-8) ; 491$ & $5.1 \pm 1.9(1-22) ; 1489$ & $3.7 \pm 1.5(1-13) ; 1636$ \\
\hline Dive duration (s) & $8.0 \pm 5.0(1.5-35) ; 510$ & $5.1 \pm 2.9(1.5-23) ; 491$ & $7.3 \pm 4.61-39) ; 1489$ & $5.7 \pm 3.9(0.5-27) ; 1636$ \\
\hline No. dives $\mathrm{h}^{-1}$ & $23.4 \pm 13.9(6.6-50.8) ; 9$ & $13.2 \pm 9.7(3.5-34.2) ; 7$ & $17.1 \pm 9.5(1.8-45.4) ; 42$ & $15.4 \pm 7.8(2.3-31.3) ; 36$ \\
\hline
\end{tabular}

\section{Diving depth and duration}

A total of 4133 dives was recorded for 51 birds (28 males, 23 females) that performed 106 foraging trips. Although the maximum dive depth and duration was $22 \mathrm{~m}$ and $39 \mathrm{~s}$, respectively, the majority of dives were rather shallow $(\bar{x}=4.17 \pm 1.78 \mathrm{~m}$, Fig. $4 \mathrm{a})$ and short $(\bar{x}=6.46 \pm 4.34 \mathrm{~s}$, Fig $4 \mathrm{~b})$. Females dived significantly deeper than males (REML log-transformed depths, $F_{1,47}=12.45, \mathrm{p}<0.001$ ) (Table 3). Birds dived at similar depths in 2002 and 2003 (REML, $F_{1,47}=2.08, \mathrm{p}=0.156$ ), and the magnitude of the differences in dive depths between sexes was maintained in both years ( $\operatorname{sex} x$ year interaction, $F_{1,47}=0.82, \mathrm{p}=0.369$ ). Dives were significantly longer in females than in males (REML logtransformed depths, $F_{1,47}=10.20, \mathrm{p}=0.002$ ) (Table 3 ), but similar between years (REML, $F_{1,47}=0.02, \mathrm{p}=$ $0.88)$, with no interaction effects between the 2 factors $\left(F_{1,47}=0.02, \mathrm{p}=0.88\right)$. The foraging effort (obtained by dividing the total number of dives on a trip by the duration of the foraging trip) was on average $16.7 \pm$ 9.5 dives $\mathrm{h}^{-1}(\mathrm{n}=94)$ and was similar between sexes $\left(\right.$ REML $\left., F_{1,42}=3.42, \mathrm{p}=0.07\right)$ and years (REML, $F_{1,42}=$ $0.22, \mathrm{p}=0.63$ ) (Table 3).

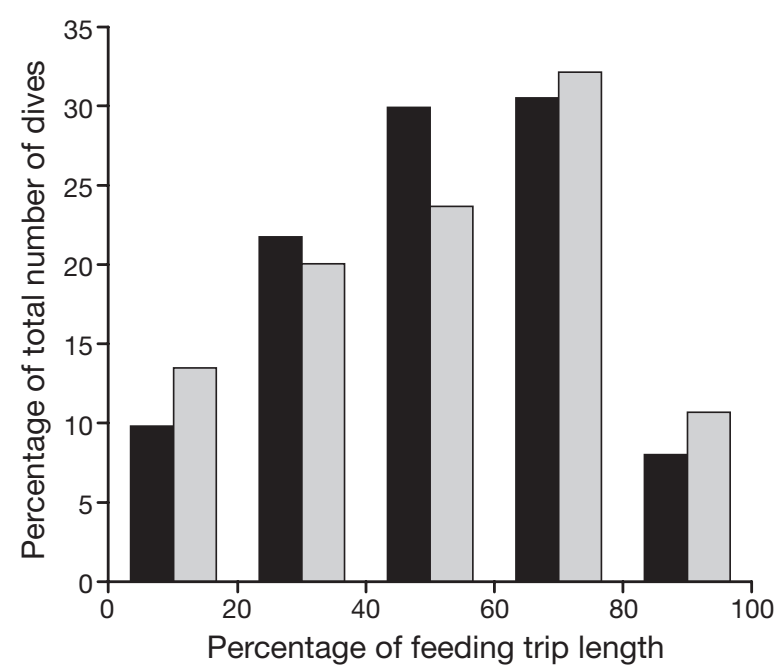

Fig. 3. Sula nebouxii. Temporal distribution of number of dives $(\mathrm{n}=3651)$ during feeding trips of 21 females (black bars) and 25 males (gray bars) at Isla Lobos de Tierra, Peru. Length of the feeding trip was divided into quintiles
Body size and mean dive depth were positively correlated (Mean dive depth $(\mathrm{m})=4.13+(0.43 \times \mathrm{PC} 1)$; $F_{1,50}=25.8, \mathrm{r}^{2}=0.33, \mathrm{p}<0.001$ ) (Fig. 5). However, when the effect of sex was examined, no significant correlation between body size and mean dive depth was found either in females (regression, $\mathrm{r}^{2}=0.015, F_{1,22}=$ $0.32, \mathrm{p}=0.57$ ) or in males (regression, $\mathrm{r}^{2}=0.049, F_{1,27}=$ 1.34, $\mathrm{p}=0.25)$.

Two dive types were recognized: V-shaped dives when the birds dived to a maximum depth and immediately returned to the surface, and U-shaped dives when horizontal or zigzagging displacement occurred at the maximum dive depth (Garthe et al. 2000). V-shaped dives were most common, with U-shaped dives occurring in $5.4 \%$ of the total immersions $(\mathrm{n}=$ 4133). Time spent at the bottom of the U-shaped dives ranged from 4 to $28 \mathrm{~s}$. Birds performed an increasing proportion of U-shaped dives with increasing maxi-

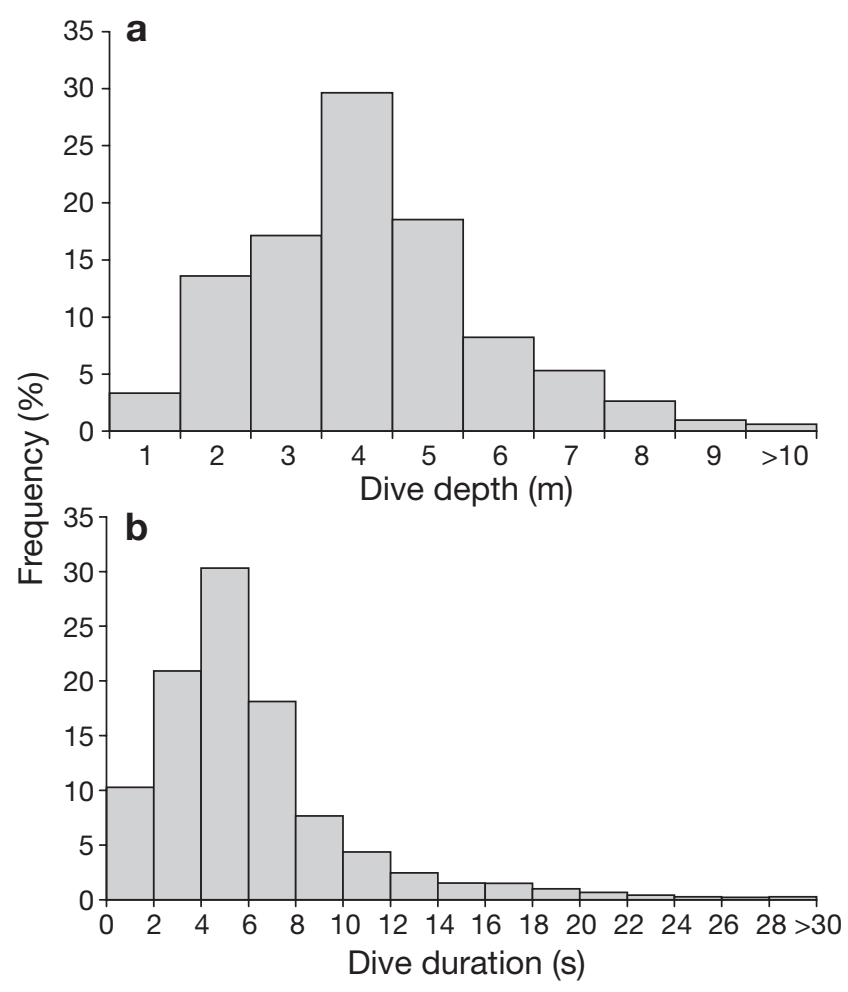

Fig. 4. Sula nebouxii. Frequency distribution of (a) dive depth and (b) dive duration 


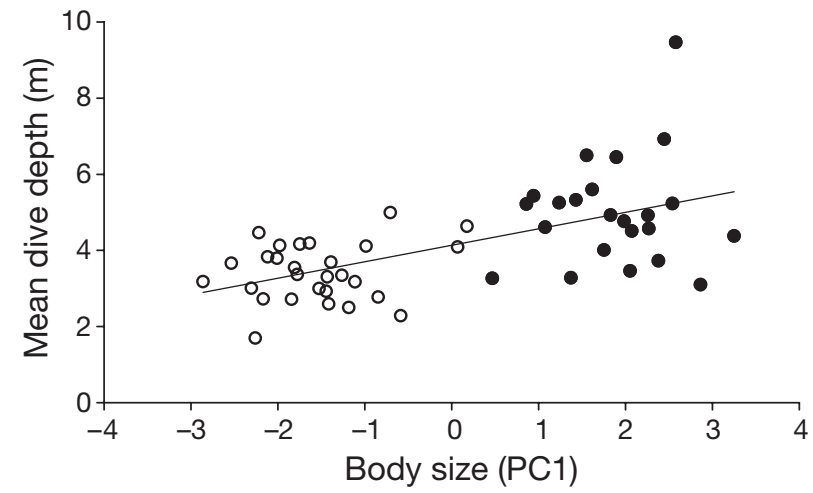

Fig. 5. Sula nebouxii. Relationship of mean dive depth (m) and body size index (Principal component analysis) for 23 females (•) and 28 males (O) at Isla Lobos de Tierra, Peru

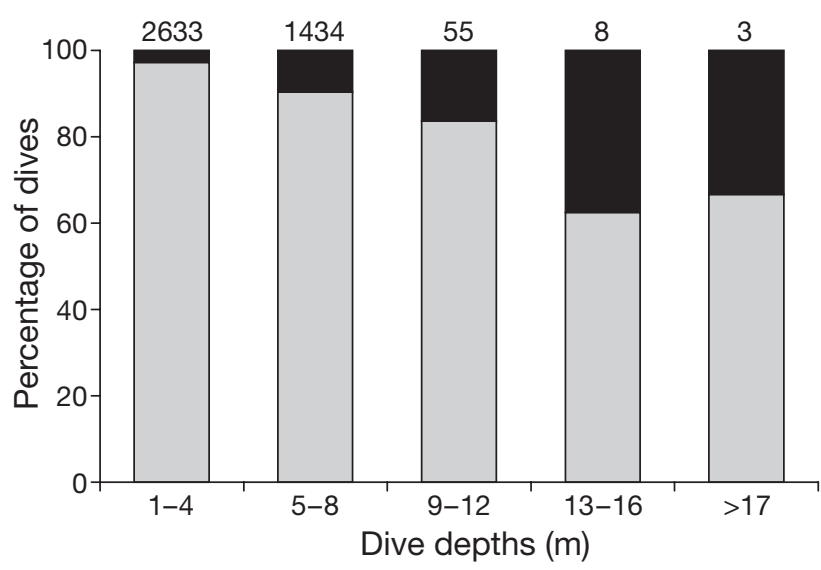

Fig. 6. Sula nebouxii. Proportions of V-shaped dives (gray bars) and U-shaped dives (black bars) at $4 \mathrm{~m}$ intervals at Isla Lobos de Tierra, Peru. Nos. above bars: numbers of dives in each depth interval

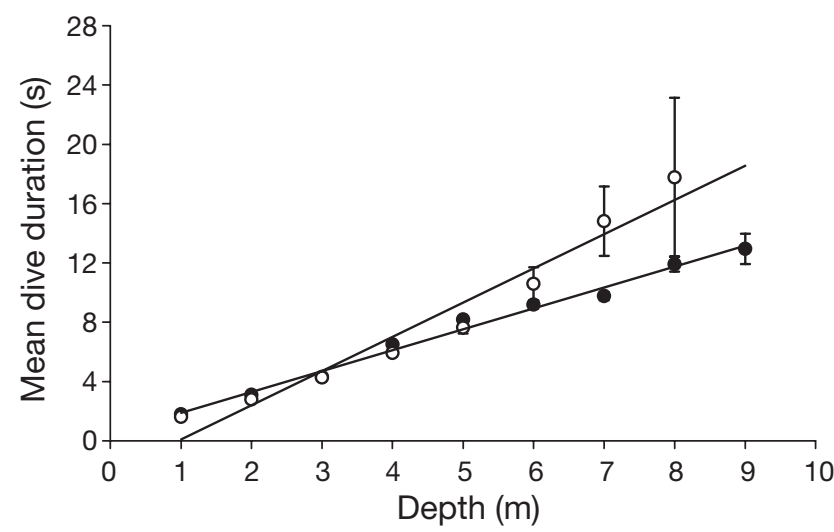

Fig. 7. Sula nebouxii. Sex-specific differences in relationship between depth and mean ( $\pm 1 \mathrm{SE}$ ) dive duration. Dive categories with more than 36 records were considered. $(\bullet)$ Females: $\mathrm{n}=23$, duration $=0.61+(1.42 \times$ depth $) ; \mathrm{r}^{2}=0.32, \mathrm{p}<0.001$; (O) males: $\mathrm{n}=28$, duration $=-1.22+(1.87 \times$ depth $) ; \mathrm{r}^{2}=0.49$, $\mathrm{p}<0.001$

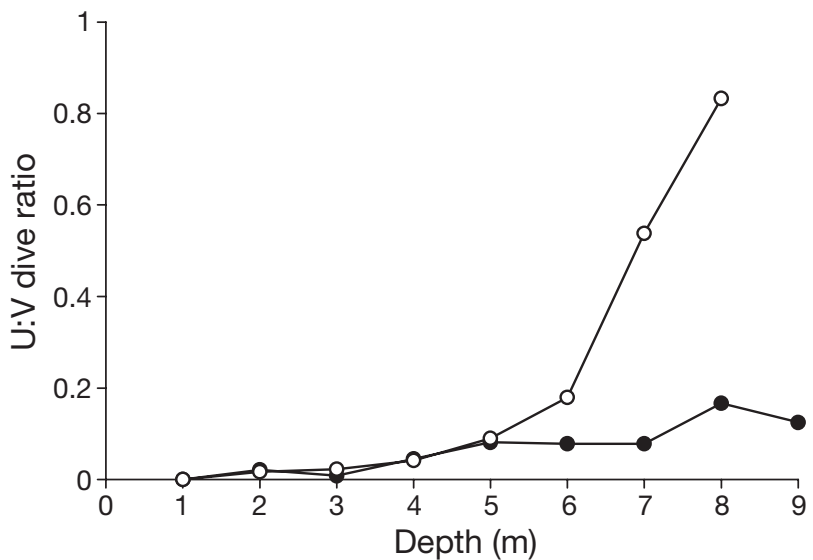

Fig. 8. Sula nebouxii. Proportion of number of U-shaped and V-shaped dives at different dive depths for 23 females $(\bullet)$ and 28 males (O) at Isla Lobos de Tierra, Peru. Only dive depths categories with $>36$ records were considered

mum dive depth (Fig. 6). The proportion of U-shaped dives was similar between sexes $\left(\chi^{2}=1.26, p=0.26\right.$, df $=1)$, but it was more frequent in $2003(6.2 \%)$ than in $2002\left(2.9 \% ; \chi^{2}=15.76, \mathrm{p}<0.001, \mathrm{df}=1\right)$.

The relationship between dive depth and duration was linear for both sexes, but the slope of the line was steeper in males (duration $=-1.22+(1.87 \times$ depth $) ; \mathrm{r}^{2}=$ $0.49, \mathrm{n}=2125)$ than in females (duration $=0.61+$ $\left(1.42 \times\right.$ depth) $\left.r^{2}=0.32, n=1978\right)$ (test of equality of regression coefficients, $F_{1,13}=5.26, p=0.039$ ) (Fig. 7) because males spent more time underwater than females at depths between 5 and $9 \mathrm{~m}$. The occurrence of U-shaped dives in relation to $\mathrm{V}$-shaped dives was up to 7 times higher in males than in females at dives deeper than $5 \mathrm{~m}$ (Fig. 8).

\section{DISCUSSION}

\section{Effects of instrumentation and accuracy of dataloggers}

We found no adverse effects of capture and handling on BFB behavior on land, and birds resumed incubation or brooding upon release. No discomfort or increase in preening activities was observed and birds did not abandon their nests when approached for recapture. Instrumented and non-instrumented BFBs in this study had similar nest desertion rates, diet composition, number of feeding trips per day, and feeding trip duration. Likewise, the proportion of birds returning to the nest with food was similar between instrumented birds $(77 \%)$ and controls ( $80 \%)$. This evidence suggests minimal short-term effects of instrumentation on the breeding and foraging performance of BFBs. Any negative impact was reduced by retrieving the devices after a bird had completed 1 foraging trip 
(usually $4 \mathrm{~h}$ ) and by attaching the datalogger underneath the tail feathers, thus eliminating the frontal impact of the device with the water surface and reducing drag during diving.

The mean dive duration of BFBs calculated from visual observations was half of that estimated from dataloggers. The reason for this discrepancy is that long immersions ( $>6 \mathrm{~s}$ ) were difficult to detect from the boat because some birds may have emerged far from the site where they plunged. Conversely, dataloggers did not record dives shorter than $2 \mathrm{~s}$ and shallower than $1 \mathrm{~m}$, and if these dives comprised a significant proportion of the total number of immersions, then the estimated mean dive duration and depth may have been an overestimate. However, visual observations of foraging birds showed that dives $<2 \mathrm{~s}$ (sampling rate of the dataloggers $=2 \mathrm{~s}$ ) were rare $(4 \%$ of the total number of dives). Likewise, the distribution of dive depths showed that shallow immersions ( 1 to $2 \mathrm{~m}$ ) were uncommon ( $3 \%$ of the total number of dives) and that BFBs usually dived at depths between 3 and $6 \mathrm{~m}(67 \%$ of dives). It is reasonable to believe that dives $<1 \mathrm{~m}$ may have been common (especially in plunge-diving species such as boobies), but undetected by the logger. Nevertheless, it is likely that the shallow dives $(<1 \mathrm{~m})$ in this hypothetical bimodal distribution were attributable to 'bathing splashes' because BFBs did not prey upon flying fish or squid at or above the surface as reported for other species of boobies (Weimerskirch et al. 2006). Thus, any possible exclusion of shallow dives $(<2 \mathrm{~s}$ and $<1 \mathrm{~m})$ would probably have had a minimal impact on our calculations.

\section{Sex-specific differences in diving behavior}

The diet composition, crop mass, trip length, number of trips per day, proportion of time in flight and resting on the water, and number of dives per hour on a trip were similar between female and male BFBs on Isla Lobos de Tierra, suggesting that both sexes feed in the same area and make a similar foraging effort. Trip length is positively correlated to the foraging range in other species of sulids (Hamer et al. 2000, Weimerskirch et al. 2005b) and short trips of male and female BFBs may indicate that both sexes forage in the proximity of the colony. Likewise, records from birds equipped with electronic compasses showed that flight orientation during the study period was similar between males and females (C. B. Zavalaga unpubl. data).

Females dived deeper and longer, and consumed larger prey than males, suggesting that feeding segregation by sex may occur underwater. Because BFBs mainly rely on the momentum of the fall to gain depth (most of their dives were V-shaped), and the magni- tude of momentum is a function of body mass, segregation of female and male BFBs in the water column may result from passive mechanisms mediated by gravitational acceleration, and not necessarily from interference competition between sexes. This observation supports the results found for red-footed boobies, in which sexual differences in dive depth, flight speed, foraging activity, and aerial agility are mediated by a disparity in body size between males and females (Weimerskirch et al. 2006). Consequently, differences in the size of prey consumed by female and male BFBs may be the result of size-dependent vertical stratification of the anchovy school, with larger fish located in deeper waters (e.g. Didrikas 2005). Likewise, males performed more U-shaped dives than females as diving depth increased, suggesting that males depended on wing flapping or foot paddling to remain in deep waters $(>5 \mathrm{~m})$. Because of their smaller size or lower buoyancy in comparison to females, males may be unable to attain greater depths by means of the momentum of their fall. Regardless of sex, large birds dived deeper and consumed larger prey than small birds, suggesting that body size plays an important role in ecological segregation (Shine 1989). Nevertheless, it was not possible to discriminate BFB size effects from sex effects because the distributions of the body sizes of the studied females and males did not overlap.

The effect of body size on foraging divergence between sexes is difficult to interpret within a phylogenetic context. If body size is the main factor for an inter-sexual foraging partition then a higher degree of segregation would be expected in more dimorphic species. Results have been ambiguous and depend on the foraging variable to be measured. For example, females and males of the highly dimorphic brown booby dive at similar depths (Lewis et al. 2005), but females dive deeper than males in the less dimorphic red-footed booby (Weimerskirch et al. 2006), and the monomorphic northern gannet (Lewis et al. 2002). Male brown boobies made longer trips than females, but no differences between sexes were found in the red-footed booby (Lewis et al. 2005, Weimerskirch et al. 2006) and the northern gannet (Lewis et al. 2002). Larger wing loading allows male wandering albatrosses to exploit windier regions of the sub-antarctic/ antarctic, whereas subtropical and tropical regions are more optimal for females with lower wing loads (Shaffer et al. 2001). Conversely, some aspects of the foraging behavior of males and females of highly dimorphic species such as magnificent frigatebirds Fregata magnificens (Calixto-Albarrán \& Osorno 2000) and northern skuas Catharacta skua (Catry et al. 1999) are alike. Thus, it is still unclear whether sex-specific differences in foraging behavior are mediated by body size or any other factor related to sex. 
Other hypotheses related to sex-specific divergence of foraging behavior do not apply to BFBs. Sexual differences in energy or nutrient requirements such as timing or extent of the feather molt (Lewis et al. 2002) may lead to differential foraging behavior, but the timing of molt in BFBs was similar in males and females. Likewise, calcium requirements for eggshell formation or calcium deficiency after oviposition did not necessarily create foraging differences because male and female BFBs consumed similar prey and, if necessary, females could obtain calcium from mollusk shells available on beaches near their colonies (as do other seabird species; Zavalaga \& Paredes 1998).

\section{Interspecific comparisons of diving behavior}

Within the Sulidae, the diving capabilities of BFBs recorded in the present study are remarkable, and exceed previous observations (Nelson 1978). Mean and maximum dive depths of BFBs are similar to those of the larger northern (2 times heavier) and cape gannets (1.5 times heavier), and greater than those of their smaller tropical congeners the brown (16 to 22\% lighter) and red-footed boobies (27 to $46 \%$ lighter) (Table 4). Unlike other specialized diving seabirds such as penguins and alcids, sulids do not fit allometric equations relating body mass and maximum dive depths (Garthe et al. 2000), perhaps because they do not rely on physiological traits related to body size such as oxygen stores or the ability to metabolize anaerobically (Schreer \& Kovacs 1997). Pelagic-fish predators such as northern gannets (Garthe et al. 2000), cape gannets (Ropert-Coudert et al. 2004a), and BFBs dive deeper than brown and red-footed boobies that capture flying fish at or above the surface (Hertel \& Balance 1999, Lewis et al. 2004, Weimerskirch et al. 2005a). These differences suggest that prey behavior and vertical distribution rather than body size determine the observed diving capabilities of sulids.

A higher dive rate of BFBs in comparison to other sulids resulted from their shorter foraging trips (Table 4) and the occurrence of plunges during the whole trip. Some aspects of the diving behavior of incubating BFBs on Isla Lobos de Tierra in 2002 and incubating tropical boobies on Johnston Atoll and Europa Island (Table 4) are conflicting and consistent with differences in foraging behavior and in marine productivity (Weimerskirch et al. 2005b). In non-El Niño years, food supply in the Peruvian upwelling ecosystem is usually abundant, and available for BFBs near their breeding grounds (Ganoza et al. 2000). In contrast, marine productivity is poor in tropical waters, where boobies must travel longer distances and adjust their foraging behavior to unpredictable conditions (Lewis et al. 2004, Weimerskirch et al. 2005a).

Table 4. Interspecific comparisons of foraging variables for 5 species of sulids

\begin{tabular}{|c|c|c|c|c|c|c|}
\hline Species/Locality & $\begin{array}{l}\text { Dive de } \\
\text { mean }\end{array}$ & $\begin{array}{l}\text { th }(\mathrm{m}) \\
\max .\end{array}$ & $\begin{array}{c}\text { Trip } \\
\text { length (h) }\end{array}$ & $\begin{array}{l}\text { No. dives } \\
\text { trip }^{-1}\end{array}$ & $\begin{array}{l}\text { Dives } \mathrm{h}^{-1} \\
\text { (on a trip) }\end{array}$ & Source \\
\hline \multicolumn{7}{|l|}{ Northern gannets } \\
\hline Bass Rock ${ }^{\mathrm{a}}$ & 4.71 & 18.00 & 22.34 & 47.75 & 1.50 & Lewis et al. (2002) \\
\hline Funk Island & 5.20 & 22.00 & & & & Garthe et al. (2000) \\
\hline North Sea & $19.70^{\mathrm{b}}$ & $34.00^{\mathrm{b}}$ & & & & Brierley \& Fernandes (2001) \\
\hline \multicolumn{7}{|l|}{ Cape gannets } \\
\hline Bird Island & 3.60 & 5.60 & 8.50 & 66.00 & 7.76 & Grémillet et al. (2004) \\
\hline Bird and Malgas Islands & 3.39 & 9.67 & & & & Ropert-Coudert et al. (2004a) \\
\hline Malgas Island & 3.40 & 4.30 & 22.60 & 68.00 & 3.00 & Grémillet et al. (2004) \\
\hline Malgas Island & 12.60 & & & & & Adams \& Walter (1993) \\
\hline \multicolumn{7}{|l|}{ Red-footed booby } \\
\hline Europa Island & & 9.70 & & & & Le Corre (1997) \\
\hline Europa Island & 0.87 & 2.40 & 5.50 & & 4.40 & Weimerskirch et al. $(2005 a, b)$ \\
\hline Johnston Atoll & $0.80^{\mathrm{c}}$ & 6.00 & 14.00 & 31.70 & 2.40 & Lewis et al. $(2004,2005)$ \\
\hline \multicolumn{7}{|l|}{ Brown booby } \\
\hline Johnston Atoll & $0.85^{\mathrm{c}}$ & 6.00 & 6.70 & 25.30 & 3.80 & Lewis et al. $(2004,2005)$ \\
\hline \multicolumn{7}{|l|}{ Blue-footed booby } \\
\hline Lobos de Tierra Island & 4.17 & 22.00 & 3.17 & 38.00 & 16.70 & This study \\
\hline \multicolumn{7}{|c|}{${ }^{a}$ Only data from females are shown } \\
\hline \multicolumn{7}{|c|}{$\begin{array}{l}\text { balues obtained from echosounder mounted on autonomous underwater vehicle (all other values in this table derived from } \\
\text { time-depth meters or capillary tubes) }\end{array}$} \\
\hline \multicolumn{7}{|c|}{${ }^{\mathrm{c}}$ Values estimated from authors' graphs } \\
\hline
\end{tabular}




\section{BFBs as predators of Peruvian anchovies}

BFBs on Isla Lobos de Tierra fed predominantly on Peruvian anchovies and the diving behavior recorded in this study seems to be linked to the vertical distribution, behavior, and availability of this small, schooling fish. Peruvian anchovies exhibit diel vertical migration, rising to the surface at night and remaining in deeper water strata ( 2 to $30 \mathrm{~m}$ ) during the day (Ganoza et al. 2000). Thus, as a diurnal predator, BFBs are forced to penetrate a few meters into the water column to access their main prey, as illustrated by the fact that the deepest dives $(>10 \mathrm{~m})$ occurred around mid-day when anchovy schools are even deeper (Jordán 1971).

Likewise, sulids are plunge-divers, using the momentum of their fall to gain depth (Nelson 1978). Northern and cape gannets usually perform underwater wing flapping or foot paddling to reach additional depth or to swim horizontally while chasing their prey (Garthe et al. 2000, Ropert-Coudert et al. 2004b). Brown and Peruvian boobies may maintain long immersion by underwater swimming using wing or foot propulsion as reported by Nelson (1978), but Nelson's observations have not been repeated and it is not known whether this feeding technique occurs in other tropical boobies. BFBs occasionally swim horizontally at the bottom of the dive (U-shaped dives accounted for $5 \%$ of all dives). Nevertheless, the majority of immersions consisted of V-shaped dives in which boobies reached their maximum depth and then immediately ascended to the surface. $\mathrm{V}$-shaped dives performed by northern gannets may be associated with the capture of large pelagic fish such as mackerel, herring, and saury, whereas U-shaped dives are directed at deep schooling fish such as capelins (Garthe et al. 2000). The former dives need to be fast to anticipate the escape of fishes with high burst speeds, whereas the latter pursue small fishes that cannot be individually detected from the air (Garthe et. al 2000).

Given that BFBs fed predominantly on Peruvian anchovies in the top few meters of the water column, why were $\mathrm{V}$-shaped dives more common than Ushaped dives? We hypothesize that the extensive use of V-shaped dives of BFBs is aimed at depolarization of the anchovy school (i.e. at forcing the fish to act independently), since single fish within a big school cannot be targeted by the boobies from the air. The rapid descent phase of the dive may break up a school, making the fish more susceptible to predation. Conspicuous coloration of other piscivore endotherms such as penguins and dolphins has the same effect on schooling fish (Wilson et al. 1987). Once the school is depolarized, the boobies can passively ascend to the surface seizing individual anchovies from below. The pigment patterns of anchovies (blue and silver on the dorsal and ventral surfaces, respectively) make them more conspicuous to predators from below than from above (Bond 1996). The higher occurrence of U-shaped dives in 2003 coincides with a more diversified diet, which indicates that these dives may be associated with fish other than anchovies. The majority of instrumented birds consumed exclusively anchovies, and no reliable relationship between individual diving behavior and prey type could be made. Nevertheless, 1 instrumented bird that captured 4 jack mackerel, and 2 short-finned butterfish on a feeding trip with $10 \mathrm{U}$-shaped dives, attained deeper $($ maximum $=22 \mathrm{~m}$, mean $=12 \mathrm{~m}$ ) and longer (maximum $=34.5 \mathrm{~s}$, mean $=21.4 \mathrm{~s}$ ) dives in comparison to other birds.

BFBs are able to exploit other prey that vary in size, behavior, and distribution (Jahncke \& Goya 2000). At least 28 species of fishes and 1 species of squid have been recovered from BFB regurgitations on Isla Lobos de Tierra. Diet composition changed with oceanographic conditions, with diversity of prey species increasing with increasing SST (Janhcke \& Goya 2000, this study). During the strong El Niño Southern Oscillation in 1998, when anchovies were not available near Isla Lobos de Tierra, BFBs relied on other fishes and did not abandon the island, as did Peruvian boobies which are anchovy specialists (Jahncke \& Goya 2000). The predictable seasonal variations and random interannual changes in the spatial distribution and abundance of the Peruvian anchovy (Ganoza et al. 2000) would favor a flexible foraging strategy for BFBs. Thus, it is likely that BFB foraging behavior resembles those of tropical boobies during El Niño events, when prey are more dispersed and less available to their predators.

\section{CONCLUSIONS}

The diving behavior of BFBs on Isla Lobos de Tierra appears to be linked to the behavior and distribution of their main prey, the Peruvian anchovy. Because the availability of this small schooling fish varies both seasonally and annually as a consequence of temporal oceanographic changes, BFBs would be expected to exhibit a flexible foraging strategy. Diving depths attained by BFBs exceeded previous expectations, being similar to those of the larger temperate gannets and much deeper than those of tropical boobies. These differences seem to be associated with the vertical distribution of their main prey rather than body size.

The fact that BFBs fed close to their breeding sites during this study explains the lack of sexual differences in the duration of feeding trips, number of trips in a day, diet composition and diving effort. Recurrent feeding frenzies reflected conditions of high food availability during the study period. However, females 
dived deeper and longer and consumed larger prey than males, indicating that segregation may occur underwater. Regardless of sex, larger birds dived deeper and consumed larger prey than smaller birds, but with the data available it was not possible to discriminate between the effects of body size and those of sex.

Sexual differences in foraging behavior may emerge under poor food conditions (e.g. El Niño events), when food competition increases. Thus, temporal and spatial comparisons of BFB foraging behavior are necessary to elucidate the relationships between food competition and feeding niche segregation between sexes.

New approaches to discriminate the effects of body size and any other factor related to sex are also necessary to investigate whether sex-specific foraging behavior in sulids is mediated by body size. For example, intraspecific comparisons of foraging variables between a group comprised of males and females of similar size (within the overlapping range of size distributions) and another group in which the females are larger than the males (the commonest phenotype in a population) would separate the 2 effects.

Acknowledgements. We thank M. Aguilar, R. Both, A. C. Dávila, E. Flores, G. Mori and M. Reque for their logistic support and efforts that made the fieldwork on Isla Lobos de Tierra possible. We are also grateful to PROABONOS for permission to work on Isla Lobos de Tierra and to D. Nardi who spent several hours compiling and processing information from the dataloggers. J. Alfaro and E. Carranza kindly offered accommodation on the mainland and E. Goya provided the booby's metal bands. D. Anderson and 2 anonymous referees improved this manuscript with their comments and suggestions. A grant from Idea Wild to C.B.Z. provided support for this study and S.B. and L.A. received grants from the University of Pisa and from Ministero della Ricerca Scientifica e Tecnologica.

\section{LITERATURE CITED}

Adams NJ, Walter CB (1993) Maximum diving depths of Cape gannets. Condor 95:734-736

Anderson DJ, Ricklefs RE (1987) Radio-tracking masked and blue-footed boobies (Sula spp.) in the Galápagos Islands. Natl Geogr Res 3:152-163

Anderson DJ, Ricklefs RE (1992) Brood size and food provisioning in masked and blue-footed boobies (Sula spp.). Ecology 73:1363-1374

Andersson MB (1994) Sexual selection. Princeton University Press, Princeton, NJ

Andersson MB, Norberg RÅ (1981) Evolution of reversed sexual size dimorphism and role partitioning among predatory birds, with a size scaling of flight performance. Biol J Linn Soc 15:105-130

Benvenuti S, Dall'Antonia L, Lyings P (2001) Foraging behavior and time allocation of chick-rearing razorbills Alca torda at Gaesholmen, central Baltic Sea. Ibis 143: 402-412

Benvenuti S, Dall'Antonia L, Falk K (2002) Diving behaviour differences between incubating and brooding Brünnich's guillemots, Uria lomvia. Polar Biol 25:474-478

Bond C (1996) The biology of fishes, 2nd edn. Saunders College, Fort. Worth, TX

Brierley AS, Fernandes PJ (2001) Diving depths of northern gannets: acoustic observations of Sula bassana from an autonomous underwater vehicle. Auk 118:529-534

Calixto-Albarrán I, Osorno JL (2000) The diet of the magnificent frigatebird during chick rearing. Condor 102:569-576

Castillo R, Gutierrez M, Peraltillo S, Herrera N (1999) Biomasa de los principales recursos pesqueros durante el verano de 1999. Crucero BIC Jose Olaya Balanadra 990203, de Tumbes a Tacna. Bol Inst Mar Peru 147:31-45

Catry P, Phillips RA, Furness RW (1999) Evolution of reversed sexual size dimorphism in skuas and jaegers. Auk 116: $158-168$

Darwin C (1871) The descent of man, and selection in relation to sex. Reprinted, Rand McNally, Chicago, IL

Didrikas T (2005) Distribution and activity of pelagic fish, acoustic studies in the Baltic Sea. PhD dissertation, University of Stockholm, Stockholm

Drummond H, Osorno JL, Torres R, García C, Larios HM (1991) Sexual size dimorphism and sibling competition: implications for avian sex ratios. Am Nat 138:623-641

Duffy DC (1987) Aspects of the ecology of blue-footed and Peruvian boobies at the limits of their ranges on Isla Lobos de Tierra, Perú. Colon Waterbirds 10:45-49

Ganoza F, Castillo PR, Marín D (2000) Variaciones estacionales en la distribución y biomasa de anchoveta entre 1983 y 2000. Bol Inst Mar Perú 19:157-177

Garthe S, Benvenuti S, Montevecchi WA (2000) Pursuit plunging by Northern gannets (Sula bassana) feeding on capelin (Mallotus villosus). Proc R Soc Lond B 267:1717-1722

González-Solís J, Croxall JP, Wood AG (2000) Sexual dimorphism and sexual segregation in foraging strategies of Northern giant petrels, Macronectes halli, during incubation. Oikos 90:390-398

Grémillet D, Dell'Omo G, Ryan PG, Peters G, Ropert-Coudert Y, Weeks SJ (2004) Offshore diplomacy, or how seabirds mitigate intra-specific competition: a case study based on GPS tracking of Cape gannets from neighbouring colonies. Mar Ecol Prog Ser 268:265-279

Guerra M, Drummond H (1995) Reversed size dimorphism and parental care: minimal division of labour in the bluefooted booby. Behaviour 132:479-497

Guillén V (1991) Población mensual del camanay (Sula nebouxii) en el Perú, durante 1985-86 y 1988-90. Bol Lima 76:53-58

Hamer KC, Phillips RA, Wanless S, Harris MP, Wood AG (2000) Foraging ranges, diets and feeding locations of gannets Morus bassanus in the North Sea: evidence from satellite telemetry. Mar Ecol Prog Ser 200:257-264

Hedrick AV, Temeles EJ (1989) The evolution of sexual dimorphism in animals: hypotheses and tests. Trends Ecol Evol 4:136-138

Hertel F, Balance LT (1999) Wing ecomorphology of seabirds from Johnston Atoll. Condor 101:549-556

Jahncke J, Goya E (2000) Responses of three booby species to El Niño 1997-1998. Waterbirds 23:102-108

Jordán R (1971) Distribution of anchoveta (Engraulis ringens) in relation to the environment. Investig Pesq (Barcelona) 35:113-126

Kuehl RO (2000) Design of experiments: statistical principles of research design and analysis. Duxbury Press, New York

Le Corre M (1997) Diving depths of two tropical Pelecaniformes: the red-tailed tropicbird and the red-footed Booby. Condor 99:1004-1007 
Lewis S, Benvenuti S, Dall'Antonia L, Griffiths R, Money L, Sherratt TN, Wanless S, Hamer KC (2002) Sex-specific foraging behavior in a monomorphic seabird. Proc R Soc Lond B 269:1687-1693

Lewis S, Schreiber EA, Daunt F, Schenk GA, Wanless S, Hamer KC (2004) Flexible foraging patterns under different time constrains in tropical boobies. Anim Behav 68: 1331-1337

Lewis S, Schreiber EA, Daunt F, Schenk GA, Orr K, Adams A, Wanless S, Hamer KC (2005) Sex-specific foraging behavior in tropical boobies: does size matter? Ibis 147: 408-414

Nelson JB (1978) The Sulidae: gannets and boobies. Oxford University Press, Oxford

Paredes R, Jones IL, Boness DJ (2005) Reduced parental care, compensatory behaviour and reproductive costs of thickbilled murres equipped with data loggers. Anim Behav 69:197-208

Ropert-Coudert Y, Grémillet D, Kato A, Ryan PG, Naito Y, Le Maho Y (2004a) A fine-scale time budget of cape gannets provides insights into the foraging strategies of coastal seabirds. Anim Behav 67:985-992

Ropert-Coudert Y, Grémillet D, Ryan P, Kato A, Naito Y, Le Maho Y (2004b) Between air and water: the plunge dive of the Cape gannet Morus capensis. Ibis 146:281-290

Schreer JF, Kovacs KM (1997) Allometry of diving capacity in air-breathing vertebrates. Can J Zool 75:339-358

Editorial responsibility: Otto Kinne (Editor-in-Chief), Oldendorf/Luhe, Germany
Shaffer SA, Weimerskirch H, Costa DP (2001) Functional significance of sexual dimorphism in wandering albatross, Diomedea exulans. Funct Ecol 15:203-210

Shine R (1989) Ecological causes for the evolution of sexual dimorphism: a review of the evidence. Q Rev Biol 64: 419-461

Velando A, Alonso-Alvarez C (2003) Differential body condition regulation by males and females in response to experimental manipulations of brood size and parental effort in the blue-footed booby. J Anim Ecol 72:846-856

Weimerskirch H, Le Corre M, Jaquemet S, Marsac F (2005a) Foraging strategy of a tropical seabird, the red-footed booby, in a dynamic marine environment. Mar Ecol Prog Ser 288:251-261

Weimerskirch H, Le Corre M, Ropert-Coudert Y, Kato A, Marsac F (2005b) The three-dimensional flight of redfooted boobies: adaptations to foraging in a tropical environment? Proc R Soc Lond B 272:53-61

Weimerskirch H, Le Corre M, Ropert-Coudert Y, Kato A, Marsac F (2006) Sex-specific foraging behaviour in a seabird with reversed sexual dimorphism: the red-footed booby. Behav Ecol 146:681-691

Wilson RP, Ryan PG, James A, Wilson MP (1987) Conspicuous coloration may enhance prey capture in some piscivores. Anim Behav 35:1558-1560

Zavalaga CB, Parades R (1998) Why do Humboldt Penguins feed on sea shells? Ostrich 69:377-378

Submitted: April 19, 2006; Accepted: September 7, 2006

Proofs received from author(s): March 29, 2007 